\title{
MERCADO INSTITUCIONAL DE ALIMENTOS NOS MUNICÍPIOS DE CAMPO NOVO DO PARECIS E TANGARÁ DA SERRA - MATO GROSSO - BRASIL
}

\author{
MACHADO, Núbia Menezes ${ }^{1}$ \\ LAFORGA, Gilmar ${ }^{2}$ \\ RAMBO, José Roberto ${ }^{3}$ \\ FRANÇA, Raimundo Nonato Cunha de ${ }^{4}$
}

Recebido em: 2020.04 .22

Aprovado em: 2021.02.11

ISSUE DOI: $10.3738 / 1982.2278 .3778$

\begin{abstract}
RESUMO: Objetivou-se neste trabalho analisar o mercado institucional de alimentos nos municípios de Tangará da Serra e Campo Novo do Parecis e identificar a demanda que foi atendida pela agricultura familiar no ano de 2015 . A coleta de dados foi realizada por meio de levantamento sobre a compra de alimentos nas instituições da esfera municipal, estadual e federal localizados nos municípios. O município de Campo Novo do Parecis não atinge o percentual mínimo do valor que deve ser destinado para a compra de alimentos do Programa Nacional de Alimentação Escolar (PNAE), sendo assim, ainda existe demanda a ser atingida no município pela agricultura familiar. O município de Tangará da Serra atinge o percentual de 37\% do valor destinado para a compra de produtos alimentícios pelo PNAE, e realiza a compra de produtos através do Programa de Aquisição de Alimentos. Em relação aos principais produtos adquiridos teve predominância as olerícolas e as frutas, posto que são produtos quais os produtores têm maior experiência, facilidade e conhecimento, fornecendo principalmente produtos in natura. Os principais fornecedores dos produtos alimentícios são produtores individuais.
\end{abstract}

Palavras-chave: Agricultura Familiar, Comercialização Agrícola, Políticas Públicas.

\section{INSTITUTIONAL FOOD MARKET IN THE MUNICIPALITIES OF CAMPO NOVO DO PARECIS AND TANGARÁ DA SERRA - MATO GROSSO STATE - BRAZIL}

\begin{abstract}
SUMMARY: The aim of this work is to analyze the institutional food market in municipalities Tangará da Serra and Campo Novo do Parecis and identify to that demand is met by family farmers for 2015. Data collection was done through a survey about buying food in the institutions of local, state and federal level in the municipalities. The municipality of Campo Novo do Parecis can not reach the minimum value of the percentage to be allocated for the purchase of food through the PNAE, so there is still a demand to be met in the city by family farmers. The city of Tangará da Serra reaches a percentage of $37 \%$ of the amount allocated for the purchase of food products for PNAE, also conducts buying products through the PAA. The main products are purchased were the vegetable crops and fruits, because the producers have easier, knowledge about these products, mainly supplying fresh products. The main suppliers of food products are individual producers.
\end{abstract}

Keywords: Family Farm, Agricultural Marketing, Public Policy.

\section{INTRODUÇÃO}

A comercialização agrícola pode ser entendida como um processo organizado no qual a produção é encaminhada por canal de venda, podendo ou não sofrer transformações, até chegar ao consumidor, levando-se em consideração todas as atividades envolvidas no processo (WAQUIL; MIELE; SCHULT, 2010). O principal componente desse sistema de comercialização

\footnotetext{
${ }^{1}$ Engenheira Agrônoma. Universidade do Estado de Mato Grosso.

${ }^{2}$ Curso de Agronomia. Faculdade de Ciências Agrárias, Biológicas, Engenharia e da Saúde. Universidade do Estado de Mato Grosso. ORCID-ID - http://orcid.org/0000-0003-2768-7888

${ }^{3}$ Curso de Agronomia. Faculdade de Ciências Agrárias, Biológicas, Engenharia e da Saúde. Universidade do Estado de Mato Grosso. ORCID-ID - http://orcid.org/0000-0002-2254-7301

${ }^{4}$ Curso de Letras e Programa de Pós-Graduação em Ambiente e Sistemas de Produção. Universidade do Estado de Mato Grosso. ORCID-ID - http://orcid.org/0000-0003-4490-192X
} 
é o mercado, local onde atuam as forças de oferta e demanda, e ocorrem transferências de bens e serviços em troca de dinheiro (MARQUES; AGUIAR, 1993; ARAÚJO et al., 2011; MAGGI et $a l ., 2015)$.

O processo de comercialização apresenta-se como um dos principais problemas da agricultura familiar. $\mathrm{O}$ acesso aos mercados acaba sendo fator determinante para o funcionamento e a composição dos sistemas produtivos familiares (SILVA et al., 2014).

Os produtos produzidos nos pequenos estabelecimentos são escoados pelos canais de comercialização e de distribuição, que irão conduzir as mercadorias dos produtores até o consumidor final e, quanto maior o arranjo entre os componentes do sistema, menores serão os custos de transação associados (MAGGI et al., 2015).

No Brasil, estes produtos passaram também a ser comercializados por meio do mercado institucional, que é designado com uma configuração específica de mercado cuja redes de trocas apresentam uma estrutura particular. Em tal estrutura verifica-se normas e convenções previamente negociadas por um conjunto de organizações, sendo o papel principal assumido pelo Estado por meio de compras públicas (SCHIMITT; GUIMARÃES, 2008; GRISA, 2010).

O mercado institucional apresenta-se como uma alternativa que possibilita a inclusão da agricultura familiar e a compra de seus produtos pelo Estado nos seus diferentes níveis (federal, estadual e municipal). Ademais, busca o reconhecimento da agricultura familiar e de suas especificidades, sendo fruto de estratégias que buscam o fortalecimento da segurança alimentar. Para tanto, depende do montante dos recursos que são disponibilizados pelo Governo para a compra de alimentos quanto à quantidade de alimentos fornecidos pelos produtores (SCHNEIDER; SILVA; MARQUES, 2004; MACIEL, 2008).

Uma forma de comercialização utilizada ultimamente pelos produtores que tem recebido destaque é a adesão desses produtores aos programas nacionais, especialmente ao Programa de Aquisição de Alimentos (PAA) e o Programa Nacional de Alimentação Escolar (PNAE) (MAGGI et al., 2015).

O PAA, criado em julho de 2003 pela Lei no 10.696/2003, compunha o Programa Fome Zero, e tem como objetivo a garantia de comercialização de produtos oriundos da agricultura familiar através da articulação da produção com mercados institucionais ou à formação de estoques, subjacentes a uma permanente preocupação com a segurança alimentar. Através do programa, o governo federal garante a compra dos alimentos por preços que não podem ser nem superior e nem inferior ao preço dos mercados da região, apresentando um limite anual de R\$ $6.500,00^{5}$ para a modalidade de compra com doação simultânea (BRASIL, 2012).

\footnotetext{
${ }^{5} \mathrm{O}$ valor destinado no período de 2015 para a compra de produtos pelo PAA variou de acordo com a modalidade e com limites de valores máximos por agricultor familiar: I - Atendimento da alimentação escolar (R\$ 9.000,00); II Distribuição de alimentos ou formação de estoque público (R\$ 8.000,00); III - Formação de estoque pela agricultura
} Nucleus, v.18, n.1, abr. 2021 
O PNAE é um dos programas mais duradouros e abrangentes em funcionamento no mundo, atuando na área de alimentação escolar (PIPITONE, 2003; STURION, 2005). No entanto, somente com a Lei $\mathrm{n}^{\mathrm{o}} 11.947$, de 16 de junho de 2009, houve melhorias significativas, tais como: a extensão do programa para toda a rede pública de educação básica e de jovens e adultos, e a indicação de que, no mínimo 30\%, do repasse do Fundo Nacional de Desenvolvimento da Educação (FNDE) estejam investidos na aquisição de produtos provenientes da agricultura familiar (BRASIL, 2009).

O PNAE apresenta-se como um modelo que visa proporcionar uma alimentação saudável, com o fornecimento de frutas e hortaliças, com a proibição de bebidas que apresentam baixo valor nutricional, como refrigerantes e sucos em pó, e com a diminuição de alimentos que possuem alta quantidade de gordura, sal e açúcar (BRASIL, 2009).

Este trabalho teve por objetivo analisar e identificar a participação da agricultura familiar nos mercados institucionais dos municípios mato-grossenses de Tangará da Serra e Campo Novo do Parecis.

\section{MÉTODO}

A pesquisa foi realizada em Campo Novo do Parecis e Tangará da Serra, pertencentes às microrregiões do Parecis e de Tangará da Serra, tendo como recorte o ano de 2015. Os municípios possuem população estimada, em 2019, de 35.360 habitantes, e, 103.750 habitantes, respectivamente. Em relação ao número de estabelecimentos agropecuários, Tangará da Serra se destaca com 1.565 estabelecimentos e uma forte presença da agricultura familiar e, Campo Novo do Parecis tem apenas 269 estabelecimentos agropecuários (IBGE, 2020).

Apesar de serem municípios que estão próximos um do outro, têm processos formativos distintos, pois Tangará da Serra teve seu processo de formação a partir da colonização privada das décadas de 1960/1970, com a vinda de migrantes das regiões Sul e Sudeste. Estes foram atraídos pela propaganda oficial de que as terras eram férteis e pouco valorizadas, consolidandose um processo de ocupação produtiva inicialmente com base na produção do café e na extração de poaia ${ }^{6}$ e depois na prestação de serviços. Em contrapartida, o município de Campo Novo do Parecis é fruto do processo migratório somente nos anos 1990. O Chapadão dos Parecis, onde está localizado o referido município, registra a presença de populações indígenas da etnia parecis-halitis, desde o início do Século XX. As populações que para ali acederam recentemente são originários principalmente da região Sul e do Nordeste do país, incentivados especialmente

familiar (R\$ 8.000,00); IV - Compra com doação simultânea (R\$ 4.500,00); V - Compra direta (R\$ 4.500,00); VI PAA - Leite semestral (R\$4.000,00) (BRASIL, 2014).

${ }^{6}$ Carapichea ipecacuanha é uma planta medicinal muito utilizada pela indústria farmacêutica como fonte dos princípios ativos emetina e cefalina de ação anti-inflamatória, expectorante e vermicida. 
pela produção de grandes monocultivos como, por exemplo, o milho, a soja e o girassol (FRANÇA; MUNIS, 2012).

A coleta de dados foi realizada por meio de formulários semiestruturados, tendo como eixo orientativo o levantamento sobre a compra de alimentos nas instituições da esfera municipal (Secretaria de Saúde, Secretaria de Educação, Secretaria de Assistência Social), estadual (Assessoria Pedagógica - Secretaria de Educação do Estado de Mato Grosso - SEDUC) e federal (Instituto Federal de Mato Grosso) localizados nos municípios de Tangará da Serra e Campo Novo do Parecis no ano de 2015. O período da coleta de dados estendeu-se de 18/11/2015 a 11/04/2016. Os informantes foram: a) Campo Novo do Parecis: coordenadora pedagógica da SEDUC; o administrador do Centro Hospitalar Parecis "Euclides Horst"; IFMT - a diretora administrativa, financeira; a coordenadora de merenda escolar da Secretaria Municipal de Educação; b) Tangará da Serra foram: assessora pedagógica da SEDUC; nutricionista do Hospital Municipal; o coordenador da alimentação escolar do município; o chefe administrativo da Assistência Social e o responsável administrativo da COOPERVIDA ${ }^{7}$ que coordena do PAA/CDS de Tangará da Serra desde 2011.

Com essas informações foi possível determinar quais são os principais alimentos adquiridos, o custo desses produtos, as unidades consumidoras, a porcentagem do volume final demandado que é suprida pela agricultura familiar e o valor que os municípios direcionam para a agricultura familiar. Os produtos adquiridos pelas unidades consumidoras foram classificados em: frutas, olerícolas, carnes, leite e seus derivados, e outros ${ }^{8}$.

A tabulação dos dados foi realizada nos programas Microsoft Excel e Word e os resultados e sua análise apresentados em figuras e tabelas.

\section{RESULTADO E DISCUSSÃO}

\subsection{Mercado Institucional em Campo Novo do Parecis no ano de 2015}

No município de Campo Novo do Parecis a Secretaria Estadual de Educação (SEDUC) e a Secretaria Municipal de Educação (SEMEC) destinam à compra de alimentos para a merenda escolar um valor de aproximadamente $\mathrm{R} \$ 1.185 .682,65$, sendo que, deste valor $\mathrm{R} \$ 268.705,74$ foi disponibilizado para a compra de produtos da agricultura familiar. Compreendendo, assim, a uma porcentagem de $23 \%$ do valor destinado para a compra dos produtos, não atingindo o valor mínimo que deve ser utilizado na compra de gêneros alimentícios como disposto na Lei ${ }^{\circ}$ $11.947 / 2009$

\footnotetext{
${ }^{7}$ Cooperativa dos Produtores da Agricultura Familiar de Tangará da Serra e Região.

${ }^{8}$ Produtos menos demandados nas unidades consumidoras.
} 
Isso pode ocorrer pelo fato de que os agricultores familiares que são responsáveis pela disponibilização dos produtos para o programa atuarem, na sua maioria, individualmente, não estando organizados em cooperativa ou associação o que facilitaria que a exigência do mercado local fosse suprida pelos produtos da região.

Silva et al. (2014), estudando as dificuldades e estratégias estabelecidas a partir do acesso ao Programa Nacional de Alimentação Escolar da agricultura familiar de Unaí - MG, verificaram que as famílias que não fazem parte de cooperativas enfrentam dificuldades na organização, o que impede o acesso aos recursos para poder aperfeiçoar a produção. A adesão à cooperativa também facilitaria a comercialização dos produtos, que é um grande problema enfrentado pela agricultura familiar.

Toyoyoshi et al. (2013), em estudo realizado no estado São Paulo, ressaltam que os municípios podem não ter sucesso nas Chamadas Públicas, pelos agricultores não estarem devidamente preparados, não estarem organizados em cooperativas ou associações, não terem assistência técnica e nem capacitação para realizar produção em larga escala.

Para a agricultura familiar, as cooperativas e associações se mostram como um importante instrumento, pois os agricultores estarão organizados, podendo agregar valor aos produtos, o que pode facilitar a inserção da produção no mercado (COSTA; AMORIM JUNIOR; SILVA, 2015).

A diferença entre o total destinado à merenda escolar em Campo Novo do Parecis e o destinado à compra oriunda da agricultura familiar é no valor de R\$916.976,91 (77\%). Esses recursos, gastos com outros fornecedores, principalmente supermercados, são distribuídos da seguinte forma: $\mathrm{R} \$ 288.620,59$ corresponde ao valor destinado para a compra de alimentos industrializados, como os achocolatados, macarrão, panificação, óleo de soja, sal entre outros; $\mathrm{R} \$ 143.307,70$ são destinado para a compra das olerícolas; $\mathrm{R} \$ 162.883,94$ para a compra das frutas; $\mathrm{R} \$ 149.776,16$ para a compra de leite e derivados; $\mathrm{R} \$ 170.000,62$ para a compra de carnes; e para a compra de outros produtos como colorau e ovos são destinados aproximadamente $\mathrm{R} \$ 2.387,90$.

Isso mostra uma demanda do município não atendida por produtos tipicamente da agricultura familiar como as olerícolas, frutas, carnes, leite, ovos e colorau que representam recursos em torno de $\mathrm{R} \$ 628.356,32$. O montante de recursos que poderiam ser absorvidos pela agricultura familiar via PNAE no município seria de $\mathrm{R} \$ 897.062,06$ ou 75,53\% de todo recurso destinado à merenda escolar, em vez de somente $23 \%$.

Entretanto segundo o FNDE (2016), o município de Campo Novo do Parecis, no ano de 2014, tinha uma participação ainda menor da agricultura familiar no PNAE, com uma porcentagem de 4,13\% do total disponibilizado para o município, ou seja, no ano de 2015 houve um representativo aumento da participação da agricultura familiar no programa. 
A maioria dos produtos adquiridos pela SEDUC e SEMEC no município de Campo Novo do Parecis (Figura 1) são as olerícolas $(37,36 \%)$, as frutas $(36,09 \%)$ e as carnes $(22,99 \%)$. Já a porcentagem de leite e seus derivados que são adquiridos é muito pequena, não atingindo $1 \%$. Por outro lado, a situação em relação ao leite e seus derivados poderá mudar substancialmente nos próximos anos, considerando que a Cooperativa do Assentamento Guapirama instalou um laticínio com capacidade de processar 5.000 litros/dia no município.

Figura 1 - Percentual de classificação dos produtos adquiridos pelo PNAE em 2015 no município de Campo Novo do Parecis - Mato Grosso - Brasil.

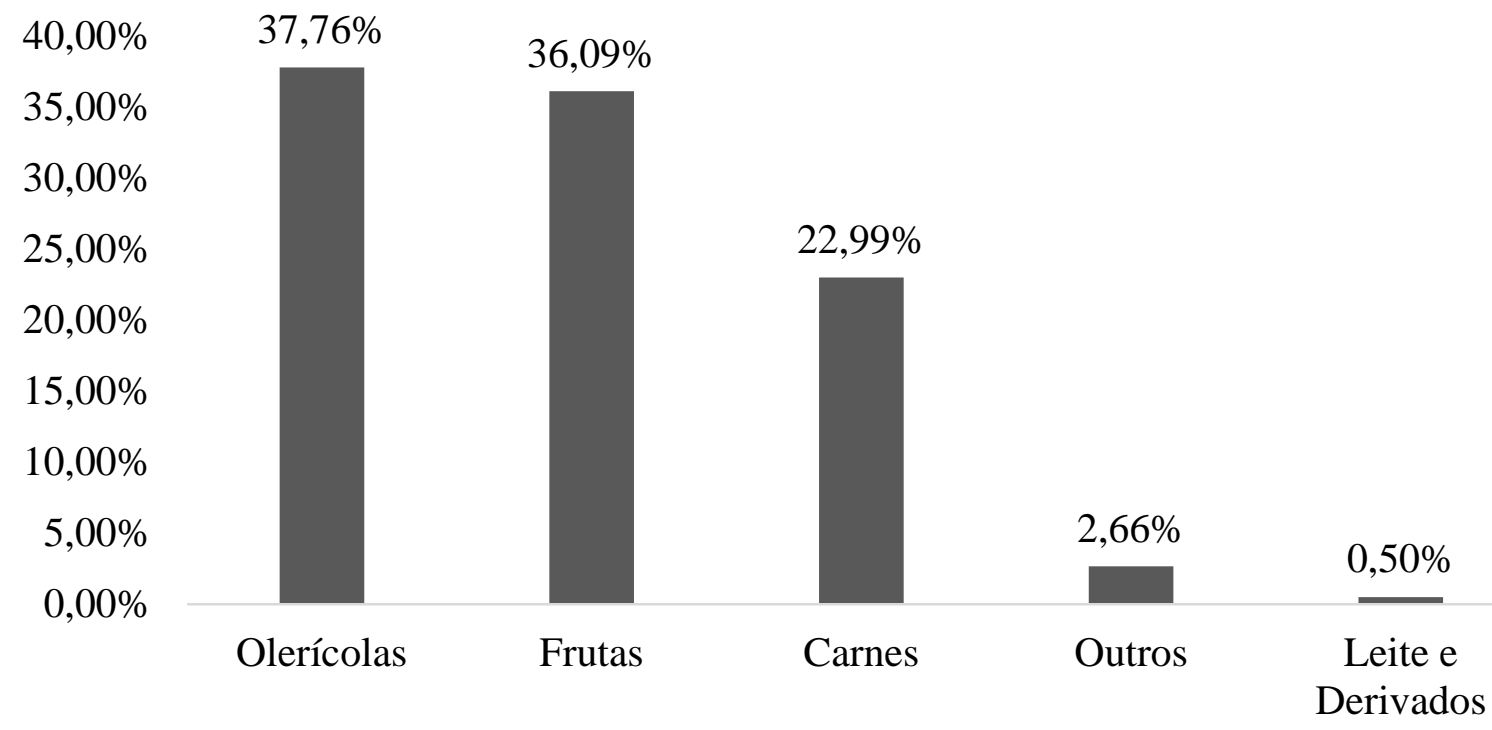

Fonte: Elaborado pelos autores.

Os produtos adquiridos por meio da compra via PNAE da agricultura familiar no município foram: a) Olerícolas: alface, rúcula, beterraba, cenoura, berinjela, couve manteiga, couve flor, cheiro-verde (salsinha e cebolinha), jiló, repolho verde, batata doce, abóbora, quiabo, pimentão verde, tomate e acelga; b) Frutas: laranja, banana, maracujá, melão, mamão, goiaba, melancia, abacaxi, tangerina e limão; c) Carnes: carne bovina, frango (coxa e sobrecoxa); d) Leite e derivados: leite e queijo muçarela; e e) Outros produtos: polpa de frutas e mel.

Esses resultados são parecidos aos obtidos por Toyoyoshi et al. (2013) quando avaliaram a aquisição de gêneros alimentícios provenientes da agricultura familiar para a alimentação escolar, onde os produtos mais demandados foram semelhantes aos produtos adquiridos da agricultura familiar pelo município de Campo Novo do Parecis.

Nesse município, não tem em execução compra de produtos pelo PAA. Porém, tem-se presente a demanda para a unidade de ensino federal (Instituto Federal de Mato Grosso), sendo que, a instituição destina um valor de $\mathrm{R} \$ 250.262,40$ por ano para a compra de alimentos, deste valor $\mathrm{R} \$ 165.288,00$ é destinado para a compra de olerícolas, $\mathrm{R} \$ 82.867,20$ para a compra de 
frutas e R $\$ 2.107,20$ para a compra de ovos. Já o hospital local designa um valor de $\mathrm{R} \$ 85.755,84$ para a compra de alimentos, sendo que $\mathrm{R} \$ 68.970,24$ são produtos industrializados e $\mathrm{R} \$ 16.785,60$ é para a compra de produtos que a agricultura familiar poderia fornecer como colorau e ovos.

\subsection{Mercado Institucional em Tangará da Serra no ano de 2015}

O município de Tangará da Serra apresenta uma maior participação da agricultura familiar na compra de gêneros alimentícios pelo PNAE, com um valor total destinado pela SEDUC e SEMEC de $\mathrm{R} \$ 4.869 .982,70$, sendo que, do total $\mathrm{R} \$ 1.801 .893,60$ é disponibilizado para a compra de produtos da agricultura familiar. Conseguindo assim, suplantar o percentual mínimo exigido pelo programa, pois o município consegue adquirir $37 \%$ dos alimentos destinados às instituições educacionais.

Segundo Saraiva et al. (2013), no ano de 2010, primeiro ano de aplicação da compra dos $30 \%$ do FNDE do segmento da agricultura familiar, 47,4\% dos municípios adquiriram alimentos da agricultura familiar para o PNAE e o percentual de compra médio foi de 22,7\%. Tendo-se que a região Sul apresentou o maior percentual de compra de alimentos da agricultura familiar (71,3\%) e o Centro-Oeste apresentou o menor (35,3\%) (SARAIVA et al.; 2013).

No município de Tangará da Serra, os agricultores familiares estão inseridos na COOPERVIDA, cooperativa que auxilia esses agricultores na comercialização dos seus produtos, o que também faz com que eles consigam suprir a demanda dos produtos no município.

No município de Tangará da Serra, do total de R $\$ 3.068 .089,40$ que corresponde aos 63\% que é destinado para a compra de alimentos, $\mathrm{R} \$ 1.098 .281,64$ é destinado para a compra de alimentos industrializados, como os achocolatados, macarrão, panificação, manteiga, vinagre, óleo de soja, entre outros. Para a compra de olerícolas é destinado R $\$ 278.116,50$; outros $\mathrm{R} \$ 19.133,21$ para a compra de frutas; para a compra de leite e derivados o valor de $\mathrm{R} \$ 33.221,00$. O valor de $\mathrm{R} \$ 1.638 .137,15$ é destinado a para a compra de carnes e para a compra de ovos são destinados $\mathrm{R} \$ 1.199,90$. Apesar de o município apresentar significativa participação da agricultura familiar, ainda é possível aumentar essa participação, pois existe demanda institucional por produtos agrícolas da agricultura familiar no município.

Os principais produtos comprados pelo município (Figura 2) são as olerícolas, que apresentam uma expressiva participação no total adquirido $(53,36 \%)$ e as frutas $(24,35 \%)$. Carne é de $13,57 \%$ e $8,72 \%$ é destinado para a compra de produtos como polpa de frutas, ovos e colorau.

Pela via do PNAE, em Tangará da Serra, os produtos olerícolas adquiridos foram: alface, acelga, batata inglesa, batata doce, chuchu, abóbora, cenoura, beterraba, tomate, cheiro verde, couve manteiga, couve flor, mandioca, pepino, pimentão e repolho verde. Frutas: abacaxi, 
mamão, laranja, banana. Carnes: carne bovina, frango e peixe. Outros: polpa de frutas, colorau e ovos.

Schwartzman (2015), ao analisar a vinculação do Programa Nacional Escolar com a agricultura familiar em municípios do estado de São Paulo, ressaltou que os principais produtos vendidos pelos agricultores são quase que em sua totalidade composta por produtos frescos, como frutas, verduras, legumes, devido aos produtores terem mais facilidade, conhecimento em relação à produção desses produtos.

Figura 2 - Percentual de classificação dos produtos adquiridos pelo PNAE em 2015 no município de Tangará da Serra - Mato Grosso - Brasil.

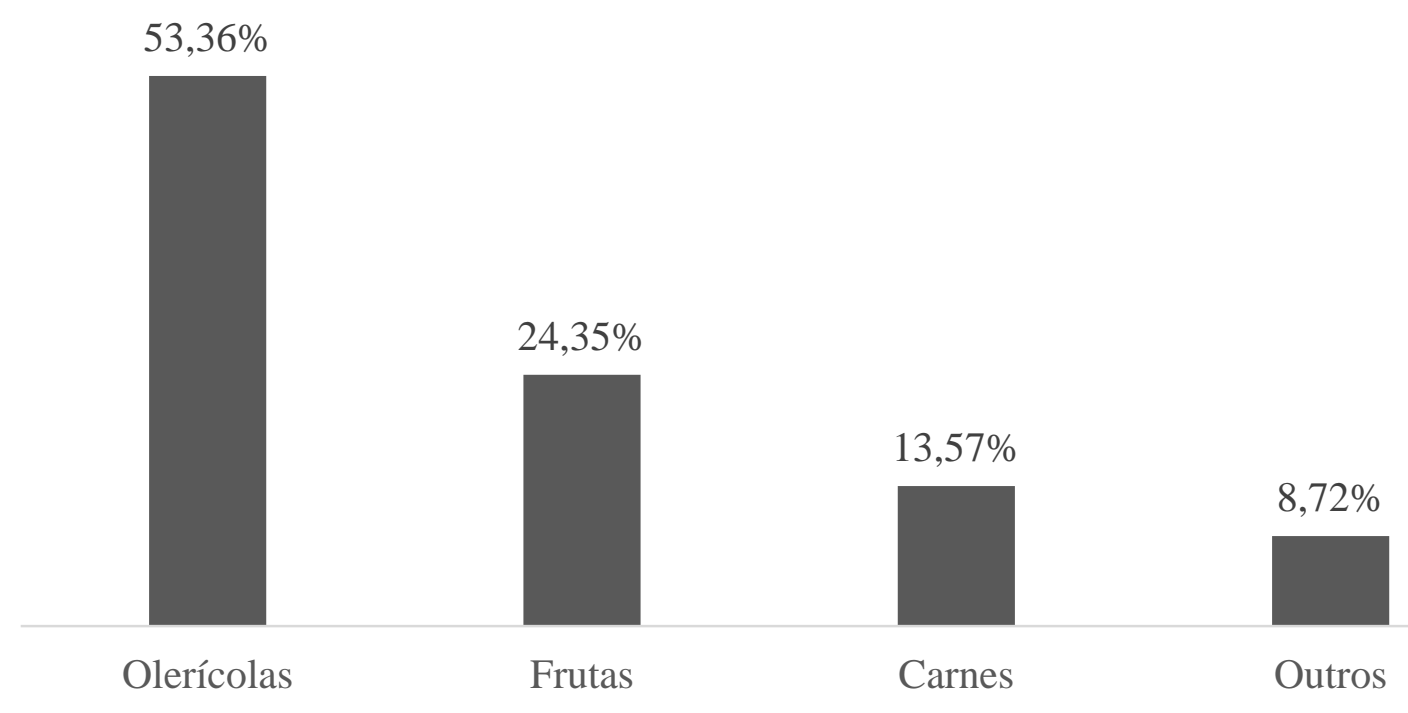

Fonte: Elaborado pelos autores.

No ano de 2014, no município de Tangará da Serra, do valor disponibilizado para a compra de alimentos pelo FNDE para o PNAE, 46,52\% foi adquirido de produtos da agricultura familiar. E, no ano de 2015, houve uma diminuição nesse valor, com uma participação de $37 \%$ do valor total disponibilizado para a compra de alimentos (FNDE, 2016).

Saraiva et al. (2013) estudaram o panorama da compra de alimentos da agricultura familiar para o PNAE nas regiões brasileiras e constataram que a região Centro-Oeste apresenta o menor percentual da compra de alimentos da agricultura familiar, o que segundo os autores ocorre devido a região apresentar características de grandes propriedades e ênfase na exportação.

O hospital municipal disponibilizou no ano de 2015 para aquisição de alimentos o valor de $\mathrm{R} \$ 8.838 .984,67$, sendo que deste valor $\mathrm{R} \$ 711.344,66$ é para a compra de olerícolas; $\mathrm{R} \$ 408.980,20$ para a compra de frutas; $\mathrm{R} \$ 1.393 .820,80$ para a compra de leite; $\mathrm{R} \$ 3.034 .509,75$ são designados para a compra de carne; e $\mathrm{R} \$ 3.290 .329,26$ para a compra de produtos industrializados. E a assistência social do município de Tangará da Serra em 2015 disponibilizou valor de $\mathrm{R} \$ 82.574,40$ para a compra de alimentos, deste, $\mathrm{R} \$ 76.870,08$ é para a compra de 
produtos industrializados e $\mathrm{R} \$ 5.704,32$ para a compra de leite. Valores estes que demonstram potencial de comercialização dos produtos da agricultura familiar de Tangará da Serra, todavia não explorada efetivamente, o PAA, em parte busca atende a essas unidades com doação de produtos adquiridos pelo programa, como se pode ver na previsão de doação do PAA aprovado em 2014, e em plena execução no ano de 2015 (Tabela 1).

No município de Tangará da Serra, o PAA, já teve 4 projetos aprovados, em 2008, 2010, 2011 e 2014, esses dois últimos sob coordenação da COOPERVIDA. Para o projeto em execução no ano de 2015, aprovado em 2014, a doação seria feita para 61 entidades do município, sendo, centros municipais de ensino (20 instituições), escolas estaduais (17 instituições), escolas municipais indígenas (02 instituições), albergue, SCFV-Cras (03 instituições), casa de recuperação de dependentes químicos, Lar do Idoso, Casa da Criança e do Adolescente e para o hospital, e previsão de atender cerca de 26.600 pessoas.

Tabela 1 - Valores previstos destinados às entidades beneficiadas pelo programa PAA 2014 no município de Tangará da Serra - Mato Grosso - Brasil.

\begin{tabular}{lr} 
Entidade Beneficiária & Valores em R\$ \\
\hline Centros Municipais de Educação & $289.224,48$ \\
Escolas Estaduais & $232.315,84$ \\
Associações & $53.546,56$ \\
Casas de Recuperação & $25.816,48$ \\
Ceja Antonio Casa Grande & $23.648,00$ \\
Hospital Municipal & $22.855,20$ \\
SCFV - Cras & $22.270,56$ \\
APAE - Associação de Pais e Amigos dos Excepcionais & $16.891,36$ \\
Sociedade Beneficiente Salmo 23 & $12.177,76$ \\
Instituto Resgate João Luiz Pizzato & $11.040,96$ \\
Centro de Referência Especial de Assist. Social & $10.960,00$ \\
C. M. A. E Ulisses Guimarães & $10.537,60$ \\
Igreja Batista no Jardim dos Ipês & $9.773,44$ \\
C. M. I. E. E. Educ. Especial Prof ${ }^{a}$ Isolde Storck & $7.900,00$ \\
Albergue Mun. “São Judas Tadeu” & $7.659,84$
\end{tabular}

Total

R\$756.618,08

Fonte: Elaborado pelos autores.

Os centros municipais de ensino e as escolas estaduais seriam as instituições a receber um maior valor para a compra dos alimentos, sendo respectivamente $\mathrm{R} \$ 278.795,04$ e $\mathrm{R} \$ 232.315,84$. 
O Programa no município beneficiaria 123 agricultores dos assentamentos Antônio Conselheiro, Vale do Sol I e II e comunidades rurais que se enquadrem como produtores da agricultura familiar, cada produtor que possui a Declaração de Aptidão ao Pronaf (DAP) pode receber até $\mathrm{R} \$ 6.150,37$ por ano, totalizando um montante de $\mathrm{R} \$ 756.618,08^{9}$ por ano para atender ao programa.

Sendo que, os principais produtos a serem adquiridos pelo PAA (Figura 3) no município seriam as frutas $(53,51 \%)$, representando mais da metade de todos os produtos previstos de aquisição, seguido pelas olerícolas $(40,76 \%)$, que são os produtos mais produzidos no município pela agricultura familiar.

Figura 3 - Percentual de classificação dos produtos previstos de aquisição pelo PAA 2014 no município de Tangará da Serra - Mato Grosso - Brasil.

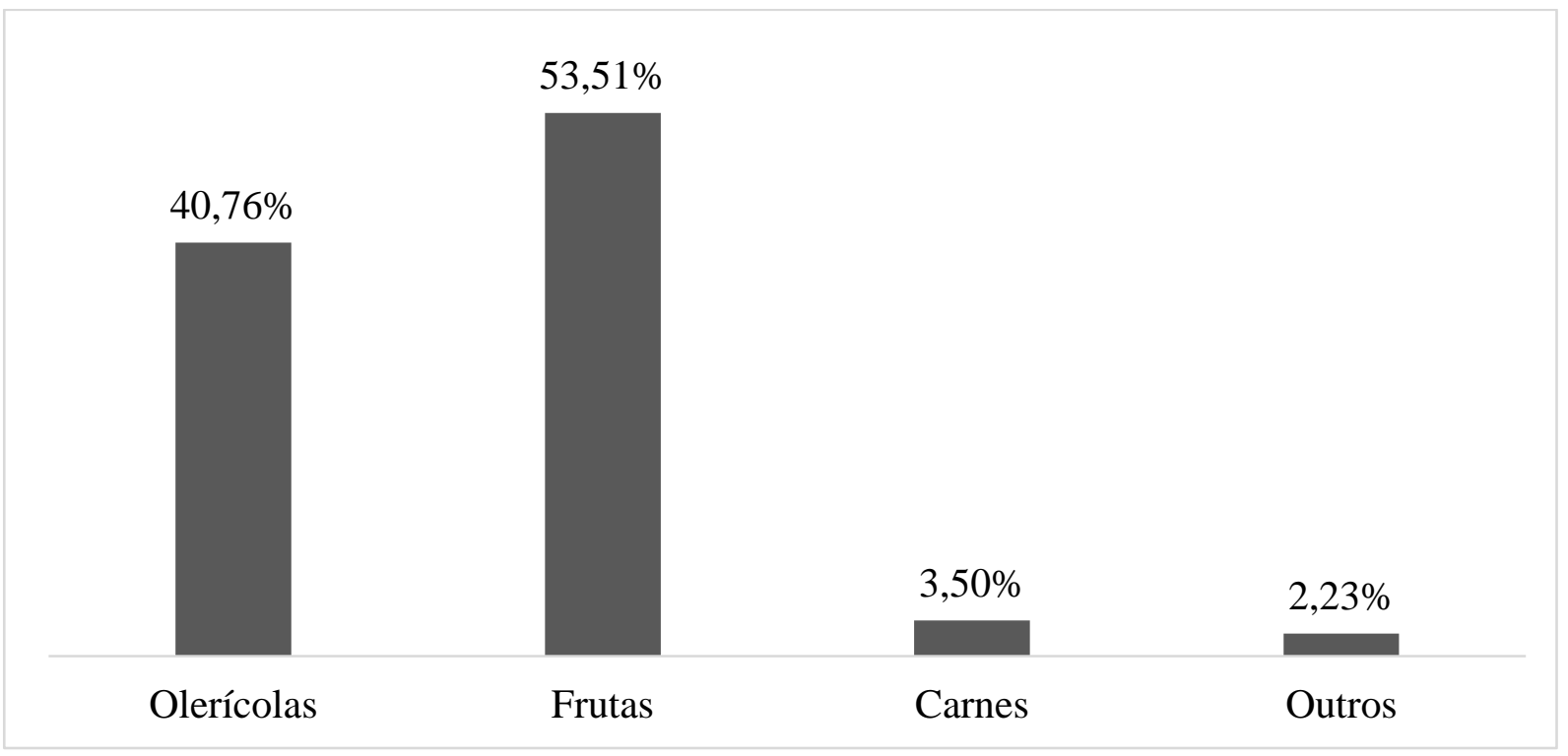

Fonte: Elaborado pelos autores.

Almeida e Ferrante (2009), no município de Araraquara-SP, comentam que as hortaliças, se destacam, representando mais da metade dos produtos comercializados via PAA no município e dos principais produtos fornecidos via PAA tinham as culturas tradicionais como mandioca, milho, abóbora, frutas e legumes de época e hortaliças.

Os produtos previstos de aquisição pelo PAA 2014 foram as olerícolas: batata doce, chuchu, abóbora, cenoura, beterraba, berinjela, tomate, mandioca, pepino, repolho verde, jiló, maxixe, pimentão, quiabo, rabanete e repolho. Frutas: abacaxi, mamão papaya, laranja, limão

\footnotetext{
${ }^{9}$ Todavia do projeto aprovado em 2014, que a pesquisa identificou o funcionamento em 2015, finalizado em 23 de dezembro de 2016, do total previsto de comercialização de $\mathrm{R} \$ 756.618,08$ somente $\mathrm{R} \$ 240.061,95$ formam efetivamente executados pela agricultura familiar do munícipio via PAA. Demonstrando ter a agricultura familiar de Tangará da Serra potencial de comercialização, via mercado institucional, da produção. Contudo, problemas da agricultura familiar relacionados a: a) estratégias de planejamento produtivo e b) organização social; ficam evidentes e dificultam a efetiva realização da comercialização via mercado institucional.
} 
taiti, maracujá, tangerina, melancia, banana. Carnes: carne bovina e frango. Outros: rapadura, açúcar mascavo, colorau e ovos. Entretanto, dessa gama de produtos previstos para comercialização, poucos foram os efetivamente comercializados pela agricultura familiar de Tangará da Serra, fator que pode estar relacionado a direcionamento da comercialização via PNAE pela Cooperativa, uma vez que não tem produtos suficientes disponibilizados pelos agricultores familiares cooperados para atender aos dois mercados institucionais.

Outro fator a considerar da oferta dos produtos, é que os agricultores familiares, tinham previsão de principalmente de fornecimento de produtos in natura, sem processamento, deixando de ganhar com o maior valor agregado de produtos processados - queijos, bebidas lácteas, geléias, polpas de frutas entre outros (SAMPAIO; ALVES, 2013; IMLAU; GASPARETTO, 2014).

Em trabalho mais recente, Silva (2020), constatou que houve forte tendência de estabilização do mercado institucional em Tangará da Serra - Mato Grosso, tendo o PNAE como centralidade.

\section{CONSIDERAÇÕES FINAIS}

O município de Campo Novo do Parecis não consegue atingir o percentual mínimo do valor que deve ser destinado para a compra de alimentos através do PNAE, diferentemente do que ocorre com o município de Tangará da Serra

Em Campo Novo do Parecis os principais fornecedores são produtores individuais, não estando estes inseridos em nenhuma cooperativa ou associação. Em Tangará da Serra, a comercialização com o PNAE, é majoritariamente realizado via COOPERVIDA, todavia, pela demanda ser alta de comercialização de produtos da agricultura familiar via mercado institucional (PNAE e PAA), a cooperativa sozinha demonstrou não ter condições de atender a demanda desses mercados.

Os produtos mais representativos de comercialização via mercado institucional nos dois municípios são as olerícolas e as frutas, ou seja, principalmente produtos in natura.

Apesar das diferenças entre os municípios de Tangará da Serra e Campo Novo do Parecis quanto à execução e capacidade de implementação sólida do PNAE e PAA, o que pode ser verificado, também, é a importância destas políticas para construção do mercado institucional nesses municípios, demonstrando que há espaço para seu crescimento e consolidação. 


\section{REFERÊNCIAS}

ALMEIDA, L.M.M.C; FERRANTE, V.L.S.B. Programas de segurança alimentar e agricultores familiares: a formação de rede de forte coesão social a partir do programa de aquisição de alimentos (PAA) no município de Araraquara-SP. In: CONGRESSO DA SOCIEDADE BRASILEIRA DE ECONOMIA E SOCIOLOGIA RURAL, 47., 2009, Porto Alegre, RS. Anais eletrônicos [...] Porto Alegre: SOBER, 2009. Acessado em 13 mar. 2016. Disponível em: http://www.sober.org.br/palestra/13/810.pdf.

ARAÚJO, H.S.de, et al. Os Principais Sistemas de Comercialização de Hortaliças. Pesquisa \& Tecnologia, v.8, n.2, 2011. Acessado em 02 fev. 2015. Disponível em: http://www.aptaregional.sp.gov.br/acesse-os-artigos-pesquisa-e-tecnologia/edicao-2011/2011julho-dezembro/1041-os-principais-sistemas-de-comercializacao-de-hortalicas/file.html.

BRASIL. Decreto $\mathbf{n}^{\circ} \mathbf{7 . 7 7 5}$ de 4 de julho de 2012. Regulamenta o art. 19 da Lei $\mathrm{n}^{\mathrm{o}}$ 10.696, de 2 de julho de 2003, que institui o Programa de Aquisição de Alimentos, e o Capítulo III da Lei $\mathrm{n}^{\mathrm{o}}$ 12.512, de 14 de outubro de 2011, e dá outras providências. Diário Oficial da União, 2012. Acessado em 09 jan. 2016. Disponível em: http://www.planalto.gov.br/ccivil_03/_ato20112014/2012/Decreto/D7775.htmhttp://www.planalto.gov.br/ccivil_03/_ato20112014/2012/Decreto/D7775.htm.

BRASIL. Lei $n^{\circ} 11.947$ de 16 de junho de 2009. Dispõe sobre o atendimento da alimentação escolar e do Programa Dinheiro Direto na Escola aos alunos da educação básica. Diário Oficial da União, 2009. Acessado em 18 dez. 2015. Disponível em:

http://www.planalto.gov.br/ccivil_03/_ato2007-2010/2009/lei/111947.htm.

BRASIL. Resolução/CD/FNDE no 38 de 16 de julho de 2009. Dispõe sobre o atendimento da alimentação escolar aos alunos da educação básica no Programa Nacional de Alimentação Escolar (PNAE). Diário Oficial da União, 2009. Acessado em 02 dez. 2015. Disponível em: http://portal.mec.gov.br/index.php?option=com_docman\&view=download\&alias=8166-res03816072009-pdf\&Itemid=30192.

BRASIL. FNDE. Dados da Agricultura Familiar. Brasília, 2016. Acessado em: 27 abr. 2016. Disponível em: http://www.fnde.gov.br/programas/alimentacao-escolar/alimentacao-escolarconsultas/dados-da-agricultura-familiar.

COSTA, B.A.L.; AMORIM JUNIOR, P.C.G.; SILVA, M.G. da.; As cooperativas da agricultura familiar e o mercado de compras governamentais em Minas Gerais. Revista de Economia e Sociologia Rural, v.53, n.01, 2015. Acessado em: 04 mai. 2016. Disponível em: http://www.scielo.br/pdf/resr/v53n1/0103-2003-resr-53-01-00109.pdf.

FRANÇA, R.N.C de; MUNIS, I. B. Fronteiras de Sonhos: migração, trabalho e política de identidade no Médio Norte Mato-grossense. Cáceres: Editora UNEMAT, 2012.

GRISA, C. As redes e as instituições do Programa de Aquisição de Alimentos (PAA). Revista Brasileira de Gestão e Desenvolvimento Regional, v.6, n.2, 2010. Acessado em 05 dez. 2015. Disponível em: http://www.rbgdr.net/022010/artigo5.pdf.

IBGE. Cidades. Acessado em: 14 abr. 2020. Disponível em: https://cidades.ibge.gov.br/. 
IMLAU, J.M.; GASPARETTO, V. Agregação de valor: Estudo em uma agroindústria familiar de hortifrutigranjeiro. Revista Perspectiva, v.38, n.142, 2014. Acessado em: 28 abr. 2016. Disponível em: http://www.uricer.edu.br/site/pdfs/perspectiva/142_421.pdf.

MACIEL, L.R. Mercado institucional de alimentos: Potencialidades e limites para a agricultura familiar. 2008. 115f. Dissertação (Mestrado em Agronegócios) - Faculdade de Agronomia e Medicina Veterinária, Universidade de Brasília. Acessado em 02 dez. 2015. Disponível em: http://repositorio.unb.br/bitstream/10482/1460/1/2008_Dissertacao_LucasMaciel.pdf .

MAGGI, G.R. et al. Canais de comercialização da produção agroecológica: análise de uma propriedade em São Miguel do Iguaçu (PR). Revista do Desenvolvimento Regional, v.12, n.1, 2015. Acessado em 02 dez. 2015. Disponível em:

http://seer.faccat.br/index.php/coloquio/article/view/219/187.

MARQUES, P.V.; AGUIAR, D.R.D. Comercialização de produtos agrícolas. São Paulo: Editora da Universidade de São Paulo, 1993.

PIPITONE, M.A.P. et al. Atuação dos conselhos municipais de alimentação escolar na gestão do programa nacional de alimentação escolar. Revista de Nutrição, v.16, n.2, 2003. Acessado em 02 dez. 2015. Disponível em: http://www.scielo.br/pdf/rn/v16n2/a01v16n2.pdf.

SAMPAIO, C.A.C.; ALVES, F.K. Arranjo socioprodutivo de base comunitária (APL. Com.): Um projeto piloto na comunidade do entorno da micro bacia do Rio Sagrado (Morretes/PR). Organizações Rurais \& Agroindustriais, v.15, n.1, 2013. Acessado em: 24 abr. 2016. Disponível em: www.redalyc.org/articulo.oa?id=87827903003.

SARAIVA, E.B.; et al. Panorama da compra de alimentos da agricultura familiar para o Programa Nacional de Alimentação Escolar. Ciência \& Saúde Coletiva, v.18, n.4, 2013. Acessado em 14 abr. 2020. Disponível em: http://www.scielo.br/pdf/csc/v18n4/04.pdf.

SILVA, A.N. A fome e suas relações com as políticas públicas: análise sobre os programas PBF, PNAE e PAA no município de Tangará da Serra - Mato Grosso. 2020. (Dissertação de Mestrado). Curso de Pós-graduação Stricto Sensu (Mestrado Acadêmico) Interdisciplinar em Ambiente e Sistemas de Produção Agrícola, Faculdade de Ciências Agrárias, Biológicas, Engenharia e da Saúde, Câmpus de Tangara da Serra, Universidade do Estado de Mato Grosso, 2020.

SCHIMITT, C.J; GUIMARÃES, L.A. O mercado institucional como instrumento para o fortalecimento da agricultura familiar de base ecológica. Agriculturas, v.5, n.2, 2008. Acessado em 02 dez. 2015. Disponível em: http://www.agriculturesnetwork.org/magazines/brazil/equidadee-soberania-nos-mercados/o-mercado-institucional-como-instrumento-parao/at_download/article_pdf.

SCHNEIDER, S.; SILVA, M.K.; MARQUES, P.E.M. Histórico, caracterização e dinâmica recente do Pronaf-Programa Nacional de Fortalecimento da Agricultura Familiar. In: SCHNEIDER, S.; SILVA, M.K.; MARQUES, P.E.M. (Orgs.) Políticas públicas e participação social no Brasil rural. Porto Alegre: Editora da UFRGS, 2004. Acessado em 02 dez. 2016. Disponível em: http://www.ufrgs.br/pgdr/arquivos/394.pdf.

SCHWARTZMAN, F. Vinculação do programa nacional de alimentação escolar (PNAE) com a agricultura familiar: caracterização da venda direta e das mudanças para os agricultores familiares em municípios do estado de São Paulo. 2015. 141f. Tese (Pós- 
Graduação em saúde pública) - Universidade de São Paulo. Acessado em 23 mar. 2016. Disponível em: www.teses.usp.br/teses/disponiveis/6/6138/tde.../FlaviaSchwartzman.pdf.

SILVA, W.H. et al. Agricultura Familiar e Mercados Institucionais: uma análise acerca da operacionalização do Programa Nacional de Alimentação Escolar no município de Unaí, MG. In: CONGRESSO DA SOCIEDADE BRASILEIRA DE ECONOMIA E SOCIOLOGIA RURAL, 52. 2014, Goiânia. Anais eletrônicos... Goiânia: SOBER, 2014. Acessado em 25 jan. 2016. Disponível em: http://www.inesc.br/engenharia/wp-content/uploads/2014/08/AGRICULTURAFAMILIAR-E-MERCADOS-INSTITUCIONAIS-uma-an\%C3\%A1lise-acerca-daoperacionaliza\%C3\%A7\%C3\%A3o-do-Programa-Nacional-de-Alimenta\%C3\%A7\%C3\%A3oEscolar-no-munic\%C3\%ADpio-de-U.pdf.

STURION, G.L. et al. Fatores condicionantes da adesão dos alunos ao Programa de Alimentação Escolar no Brasil. Revista de Nutrição, v.18, n.2, 2005. Acessado em 04 dez. 2015. Disponível em: http://www.scielo.br/pdf/rn/v18n2/24373.pdf.

TOYOYOSHI, J.W. et al. Avaliação da aquisição de gêneros alimentícios provenientes da agricultura familiar para à alimentação escolar. O Mundo da Saúde, v.36, n.4, 2013. Acessado em: 09 abr. 2016. Disponível em: http://www.saocamilo-sp.br/pdf/mundo_saude/106/1829.pdf.

WAQUIL, P.D.; MIELE, M.; SCHULTZ, G. Mercados e comercialização de produtos agrícolas. Porto Alegre: Editora da UFRGS, 2010. 